\title{
Investigação de Perfis Conceituais em uma atividade experimental sobre força magnética no Ensino Médio ${ }^{+*}$
}

Ulisses A. Leitão ${ }^{1}$

Departamento de Ciências Exatas - Universidade Federal de Lavras

Lavras - MG

José Amilton Fernandes ${ }^{2}$

Escola Estadual prefeito Celso Vieira Vilela, Heliodora, MG

Escola Estadual Coronel Gabriel Capistrano, São Sebastião da Bela Vista, MG

Gilberto Lage

Colaborador do Polo UFLA (Universidade Federal de Lavras) do MNPEF/SBF

(Mestrado Profissional em Ensino de Física/Sociedade Brasileira de Física)

\section{Resumo}

O presente artigo apresenta o desenvolvimento de uma sequência didática para o ensino-aprendizagem do conceito de força magnética sobre cargas em movimento, em uma abordagem experimental semiestruturada. Descreve-se a concepção e o desenvolvimento de um protótipo experimental para medir a força magnética e discute-se as configurações testadas. Propõe-se uma estratégia de transposição didática que visa o questionamento conceitual, utilizando o conflito cognitivo como estratégia metodológica para instigar a evolução dos perfis conceituais dos estudantes, com foco na questão das relações de simetria da interação magnética. A proposta de análise se baseia na epistemologia de Bachelard e na Teoria de Perfis Conceituais. Os resultados permitem comprovar a eficácia da metodologia proposta, bem como a necessidade de fomentar a diferenciação conceitual entre as interações elétrica e magnética. $O$ uso do protótipo permite construir o conceito de regra da mão direita e sua aplicação na formalização do tema a partir da evidência experimental.

\footnotetext{
${ }^{+}$Conceptual profiles investigation in an experimental activity on magnetic force in High School

* Recebido: de junho de 2017. Aceito: novembro de 2017.

${ }^{1}$ E-mail: ulisses@dex.ufla.br; ${ }^{2}$ E-mail: joseamiltonfernandes@yahoo.com; ${ }^{3}$ E-mail: glage@ dex.ufla.br
} 
Palavras-chave: Perfis Conceituais; Obstáculo Epistemológico; Conflito Cognitivo; Ensino de Física; Interação Magnética.

\begin{abstract}
This paper presents the development of a didactic sequence for the teaching and learning of the concept of magnetic force in a structured investigative experimental approach. It describes the design and development of an experimental prototype for measuring the magnetic force and discusses the tested settings. It is proposed a didactic transposition strategy aiming to the conceptual reasoning, using the cognitive conflict as a methodological strategy to instigate the development of conceptual profiles of the students, focused on the issue of symmetry relations of the magnetic interaction. The proposal is based on the epistemology of Bachelard and the Theory of Conceptual Profiles. The results allow us to recognize the effectiveness of the proposed methodology and the need for fostering the conceptual differentiation between the electric and magnetic interactions. The use of the prototype allows you to build concept of the right hand rule and its application in the formalization of the topic from an experimental point of view.
\end{abstract}

Keywords: Conceptual Profiles; Epistemological Obstacle; Cognitive Conflict; Physics Teaching; Magnetic Interaction.

\title{
I. Introdução
}

No contexto do desenvolvimento de uma aprendizagem potencialmente significativa (AUSUBEL, 2000, MOREIRA, 2011), o ensino de força magnética e de campo magnético é um desafio para o professor de Física. Por um lado, crescem as possibilidades de relacionar a disciplina com o uso cotidiano de tecnologias que incorporam o magnetismo e as propriedades magnéticas dos materiais - ímãs especiais, motores e geradores elétricos, sistemas de gravação magnética, sensores Hall, sistema de leitura de informação digital por magnetorresistência gigante, efeito Meißner, etc. Por outro lado, a compreensão das relações de interação e de simetria no contexto do magnetismo geram dificuldades no processo de ensinoaprendizagem que exigem uma nova abordagem, já que:

... muitas questões sobre as razões para as dificuldades [de aprendizagem] permanecem sem resposta, e há uma necessidade de sugestões [de estratégias pedagógicas] para superar estas dificuldades pela melhoria do processo educacional (SAARELAINEN, 2011, p. 21. Tradução própria). 
Neste contexto duas dificuldades conceituais se destacam: (i) a diferenciação entre o comportamento magnético e o elétrico e (ii) a construção do conceito de campo vetorial. Em busca de explicações para as razões destas dificuldades, o presente artigo apresenta o desenvolvimento de uma sequência didática para o ensino-aprendizagem do conceito de força magnética sobre cargas em movimento, em uma abordagem experimental semiestruturada. Descreve-se a concepção e o desenvolvimento de um protótipo experimental, denominado balança de Ampère-Faraday, para medir a força magnética e discute-se as configurações envolvidas no experimento. Propõe-se uma estratégia de transposição didática (CHEVALLARD, 1988, 2006) que visa o desenvolvimento do questionamento conceitual pelo aluno, em que busca-se estabelecer o conflito cognitivo pela contraposição entre o previsto e o observado (SOKOLOFF; THORNTON, 1995). A abordagem proposta foi investigada pela sua aplicação em uma escola secundária e analisada no contexto teórico da Teoria de Perfis Conceituais (MORTIMER; EL-HANI, 2014).

O texto está organizado de forma a apresentar inicialmente uma revisão bibliográfica dos estudos sobre as dificuldades conceituais no ensino-aprendizagem de magnetismo. O referencial teórico e o conceito de Perfis Conceituais são detalhados a seguir. A concepção da balança de Ampère-Faraday desenvolvida e a proposta de sequência didática são descritos e discute-se, finalmente, os resultados da aplicação da proposta, análise e as recomendações nas palavras finais.

\section{Dificuldades conceituais na aprendizagem de Magnetismo}

Diversas dificuldades conceituais no processo de ensino e aprendizagem dos conceitos de campo magnético e força magnética têm sido apresentadas na literatura (NGUYEN; MELTZER, 2003; SAARELAINEN; HIRVONEN; LAAKSONEN, 2006, 2007; SCAIFE; HECKLER, 2010, 2011; LEPPAVIRTA, 2012; GUISASOLA; ALMUDÍ; ZUBIMENDI, 2004). De uma forma geral, observa-se que o conceito de campo é confundido pelo estudante com a concepção newtoniana de ação à distância, interpretando o campo como mero artifício matemático para a descrição da força. Neste contexto, vale ressaltar os estudos de Furió e Guisasola (1998). Discutindo as concepções dos estudantes em relação ao campo elétrico no contexto do referencial teórico da Teoria de Perfis Conceituais de Mortimer (1995), os autores propõem duas zonas de perfis conceituais para o conceito de campo elétrico: a zona de concepção coulombiana, caracterizada pela concepção de que a interação elétrica se dá entre as cargas por "ação a distância" e a zona de concepção maxwelliana, em que prevalece a concepção de que a "interação elétrica não mais está ligada à sua localização no substrato material, mas se estende a todo o espaço vizinho". Os autores concluem que há pouca diferenciação por parte dos estudantes entre o conceito de força e o conceito de campo, além do expresso pela relação matemática entre estes conceitos. Os resultados obtidos pelos autores mostram "que a maioria dos estudantes, mesmo no ensino superior, possuem sérias dificuldades ontológicas e epistemológicas ao aplicar o conceito de campo elétrico, preferindo en- 
tão o uso do raciocínio baseado no modelo newtoniano (concepção coulombiana) de ação a distância para resolver problemas". Essa concepção intuitiva consegue descrever de forma mais ou menos adequada o campo e a força no caso particular da interação eletrostática, dado o seu carácter colinear e radial. Entretanto, a força magnética não é colinear com o campo magnético, o que está em contradição com o conceito de ação a distância. A interação magnética tem sua simetria associada ao produto vetorial, o que fundamenta o uso generalizado da regra da mão direita para a determinação da direção da força magnética e exige habilidades de raciocínio espacial. Finalmente, existe ainda as dificuldades em se reconhecer a aplicação das leis de conservação da energia e dos momentos linear e angular, em sistemas com campos magnéticos. Como exemplo, o tratamento clássico, não-relativístico, de simples cargas pontuais em movimento viola a terceira Lei de Newton (SCANIO, 1975). Segundo este autor, a constatação de que as forças de ação e reação são diferentes quando se trata o problema de duas cargas elétricas movendo-se em direções perpendiculares, leva os professores a duas explicações conflitantes. Ou apresenta-se a explicação errônea de que a terceira lei de Newton é desrespeitada, ou joga-se a poeira para debaixo do tapete, afirmando que se considerarmos o momento do campo eletromagnético o conflito com a terceira lei não existiria.

Recentemente, Kustusch (2016) analisou o impacto das características representacionais e contextuais da formulação de problemas envolvendo o produto vetorial na utilização pelos estudantes da regra da mão direita. O estudo reafirma a constatação da grande dificuldade dos estudantes na compreensão de conceitos que envolvam o produto vetorial, pela sua característica intrínseca de exigir raciocínio espacial. Os resultados quantitativos e qualitativos do estudo evidenciam como a compreensão e análise de problemas - como os de força magnética, que envolvem três vetores no espaço 3D - podem ser fortemente influenciadas pela representação espacial dos vetores. Em especial, os resultados demonstram como a solução de problemas que exigem o que os autores definem como "raciocínio reverso" (p. ex. achar a direção do campo magnético sabendo a direção da força magnética e da velocidade), apresenta um grau de dificuldade significativamente maior do que os problemas diretos e/ou que envolvam apenas cargas positivas.

$\mathrm{Na}$ aprendizagem de tópicos relacionados ao campo elétrico, Furió e Guisasola (1998, p. 512) defendem que os estudantes "apresentam dificuldades de origem epistemológica e ontológica, não necessariamente relacionadas às suas concepções prévias". Por envolver uma simetria de interação mais complexa, as dificuldades conceituais no ensinoaprendizagem de magnetismo, entretanto, são mais críticas.

Uma das principais fontes de confusão observada no ensino aprendizagem de magnetismo é a diferenciação entre os conceitos envolvendo os conceitos de campo elétrico e magnético (SCAIFE; HECKLER, 2010, 2011). De acordo com os autores, essa confusão é mais comum em questões de força magnética quando o campo magnético é representado por polos magnéticos, do que quando é representado por linhas de campo, pois o estudante é induzido à concepção de que os polos magnéticos atraem a carga elétrica, i.e., os estudantes demonstram 
dificuldade em diferenciar os conceitos de polo magnético e carga elétrica. Note que esta questão envolve, indiretamente, a simetria da interação magnética, ou seja, o fato de que, ao contrário do campo elétrico, a força magnética não é paralela ao campo magnético. Envolve ainda a questão do que é e como definimos uma carga elétrica, e a observação de que o campo magnético interage com cargas elétricas em movimento. Neste contexto, Guisasola, Almundí e Zubimendi (2004) observaram que a maioria dos estudantes por eles investigados apresentam (i) a concepção de que cargas elétricas geram campo magnético, independentemente de seu estado de movimento; (ii) a ideia de que ímãs são corpos eletricamente carregados; (iii) uma confusão entre os conceitos de campo elétrico e campo magnético e (iv) a explicação de interação magnética como força central do tipo newtoniana/coulombiana.

Nesse contexto, até mesmo o termo "Linhas de Força" - termo presente com demasiada frequência em livros didáticos do ensino médio no Brasil como referência às "Linhas de Campo", - é um termo inadequado, já que na simetria da interação magnética, a força é perpendicular ao campo. De uma forma geral, ao apresentar a relação da força magnética em cargas em movimento com o campo magnético simplesmente prescrevendo a equação de força magnética como fato empírico, os livros textos do ensino médio induzem uma concepção mágica de mundo, em que não há subsunçores (MOREIRA, 2009), nenhuma relação com conhecimentos anteriores.

A literatura tem relatado investigações e desenvolvimento de sequências didáticas mais frequentemente para o ensino superior (CHABAY; SHERWOOD, 2006; MARR, 1999; SALOMON; ITZA-ORTIZ, 2004). No Brasil, a opção epistemológica dos currículos oficiais de subordinar a construção conceitual ao objetivo de "relacionar o conhecimento com o dia a dia", infelizmente, tem reforçado, na sala de aula e especialmente nos livros didáticos, as concepções de senso comum. Em particular, ensina-se força magnética através de experiências com ímãs, antes de se construir o conceito abstrato de campo magnético. Desta forma, podese fomentar a construção de analogias entre o campo elétrico e o campo magnético conceitualmente equivocadas, conforme observado nos estudos de Scaife e Heckler (2010, 2011).

\section{Referencial teórico: a Teoria dos Perfis Conceituais}

O referencial teórico que fundamenta a presente proposta se baseia em diferentes contribuições. Da psicogenética, (PIAGET, 2013; PIAGET; CHOMSKY, 1987), herda-se a compreensão do papel da situação problema e do conflito cognitivo como parte importante no processo de construção interna do conhecimento. Assim, privilegia-se a busca por criar um ambiente para o questionamento de obstáculos epistemológicos, (BACHELARD, 2013). Na metodologia utilizada, elaborada como uma adaptação da Aula de Demonstração Interativa (ADI) proposta por Sokoloff e Thornton (1997 e 1998), as etapas de previsão e de experimentação - etapas distintas e sequenciais - permitem a confrontação do conhecimento prévio do estudante com a observação experimental. Esta abordagem metodológica objetiva viabilizar a aprendizagem significativa, (AUSUBEL, 2000). Entretanto, não se pretende a mera substitui- 
ção conceitual como defendida por Posner e colaboradores (1982), mas a identificação da evolução do perfil conceitual (MORTIMER, 1995; MORTIMER; EL-HANI, 2014; EL-HANI et al., 2015).

Segundo Bachelard (2013), a compreensão do fracasso no processo educacional, em especial no ensino de Ciências, não deve ser buscado em fatores externos. Não é na "complexidade e fugacidade dos fenômenos", nem

... na fragilidade dos sentidos e do espírito humano: é no âmago do próprio ato de conhecer que aparecem, por uma espécie de imperativo funcional, lentidões e conflitos. É aí que mostraremos causas da estagnação e até de regressão, detectaremos causas de inércia (no processo de aprendizagem) às quais daremos o nome de obstáculos epistemológicos (BACHELARD, 2013, p. 17).

Para Bachelard, como o obstáculo epistemológico pode "encrustar-se no conhecimento não questionado", a sua identificação deve ser o ponto de partida para "colocar a cultura científica em movimento" no processo educacional.

Influenciada pela epistemologia de Bachelard e como crítica à Teoria de Mudança Conceitual (POSNER; STRIKE; HEWSON; GERTZOG, 1982), surge, nos anos 90, a Teoria de Perfis Conceituais, proposta por Mortimer (1995). Mortimer parte do pressuposto que a coexistência de diferentes modos de conceber e pensar o mundo, bem como de se expressar verbalmente sobre conceitos, são a regra e não a exceção. Tomando como referência o conceito de perfis epistemológicos de Bachelard (2013), o autor propõe o que ele denomina zonas de perfil conceitual, que representam diferentes modos de pensar sobre os conceitos, os quais são utilizados em diferentes contextos. Diferentemente dos perfis epistemológicos de Bachelard, as zonas do perfil conceitual em Mortimer podem englobar, em sua definição, aspectos ontológicos, relacionados à própria essência da natureza em estudo, e não somente os epistemológicos. Estes modos de pensar são utilizados muitas vezes de forma incoerente, tendo em vista a polissemia característica da comunicação humana. $\mathrm{O}$ uso e aplicação destes modos de pensar define, para cada indivíduo, o seu perfil conceitual. Neste sentido, Mortimer propõe (ELHANI et al., 2015) que seja necessário investigar, a partir da história da Ciência, da epistemologia, das investigações em concepções alternativas, bem como pela análise da observação direta dos processos de ensino e de aprendizagem, para construir-se o conjunto de zonas relevantes para uma determinada área de conhecimento ou conceito. O referencial teórico proposto pela Teoria dos Perfis Conceituais (EL-HANI et al., 2015) estabelece um programa de investigação em três pontos: 1) Determinar as zonas que constituem o perfil conceitual para um número relevante de conceitos científicos fundamentais para uma determinada área; 2) Investigar o modo como essas zonas aparecem em diferentes pessoas, como forma de caracterizar os perfis conceituais individuais; e 3) Investigar a interação entre os diferentes modos de pensar e modos de se expressar em ambientes reais de ensino-aprendizagem.

Não existe até o momento um estudo para modelar o perfil conceitual para interação magnética. Entretanto, devido à eventual convergência ontológica e epistemológica, bem co- 
mo à interrelação conceitual, diversas áreas podem ser representadas por um mesmo conjunto básico de zonas. Assim, acreditamos que em diversas investigações, em especial sobre o ensino de Física e Química (EL-HANI et al., 2015; SOUZA FILHO; BOSS; CALUZI, 2012; AMARAL; MORTIMER; SCOTT, 2014), o perfil conceitual básico pode ser constituído de três zonas, que podem ser remetidas aos perfis epistemológicos de Bachelard. A zona intuitiva representa o modo de pensar ingênuo, intuitivo, característico do senso comum. Esta zona se relaciona com o perfil epistemológico bachelardiano que se contenta com a "fenomenologia primeira" (BACHELARD, 2013).

À medida que a compreensão e diferenciação conceitual avançam, o primeiro degrau é representado pelo modo de pensar empírico, em que o detalhamento experimental do processo de medida exige um aprofundamento na conceituação do tópico em estudo. Este modo de pensar é característico do que Mortimer e colaboradores definem como zona empírica (AMARAL; MORTIMER; SCOTT, 2014) e tem sua base epistemológica na etapa de geometrização definida por Bachelard. Um avanço ulterior é o de integrar o conceito dentro de uma estrutura teórica explicativa e racional, definindo o que o autor denomina a zona racionalista. Nestes pontos, Mortimer e colaboradores seguem Bachelard. De fato, segundo Bachelard, "é preciso passar primeiro da imagem para a forma geométrica e, depois, da forma geométrica para a forma abstrata", (BACHELARD, 2013, p.11).

Portanto, o presente trabalho parte da identificação de um perfil conceitual para o conceito de interação magnética com estas três zonas pela ocorrência do pensamento intuitivo, empírico e racional. Esta proposta é uma formulação inicial que deverá ser objeto de estudos mais profundos posteriormente.

No contexto deste referencial teórico, o perfil conceitual de cada estudante ou grupo de estudantes é construído pela identificação de sua forma de raciocínio, através da análise de sua forma de se expressar. Em geral, todas as zonas estarão presentes no raciocínio de diferentes pessoas e são aplicadas, com maior ou menor relevância, em diferentes contextos. O perfil conceitual expressa, de forma qualitativa, a intensidade com que cada zona está presente em cada indivíduo. Neste sentido, entendemos que o avanço no processo de ensino-aprendizagem pode ser registrado pela evolução do perfil conceitual apresentado pelos estudantes, quando o seu modo de falar e se expressar evidencia a emergência de novas formas de pensar.

Vamos nos deter um pouco mais neste ponto. Segundo Mortimer, a aprendizagem de Ciência tem o papel fundamental de "aumentar a importância das zonas científicas no pensamento dos estudantes" (EL-HANI et al., 2015, p.16). Mas como se dá o processo de aprendizagem conceitual? A Teoria dos Perfis Conceituais propõe que teremos de observar dois processos inter-relacionados (EL-HANI et al., 2015). Por um lado, existe um processo cognitivo de expansão das zonas de pensamento científico, pela construção de novos modos de pensar e de expressar o raciocínio verbal. Por outro lado, o processo metacognitivo de diálogo entre as novas formas de pensar e as velhas, as novas zonas e as antigas zonas, faz com que os 
estudantes se conscientizem da diversidade de modos de pensar e estabeleçam o contexto em que cada modo de pensar é usado.

O processo de evolução do perfil conceitual é um processo dialético, em que o conflito cognitivo tem um importante papel catalisador de mudança na estrutura conceitual do estudante. Para se ter sucesso neste processo de evolução do perfil conceitual, o estudante precisa se envolver em uma etapa de integração de conhecimento. Ou seja, as novas ideias precisam se encaixar na estrutura conceitual prévia (AUSUBEL, 2000). Entretanto, estes mesmos conceitos prévios podem gerar resistência ao aprendizado de novos conceitos (BACHELARD, 2013) pelo estabelecimento de obstáculos epistemológicos. Neste processo, alguns conceitos podem ser refinados, mas outros serão descartados, sempre que não puderem se acomodar, de forma coerente, com as novas observações. Fundamental neste processo é o surgimento do conflito cognitivo ${ }^{2}$. Chinn e Brewer (1993) postulam que existem sete formas distintas de resposta ao conflito entre os conceitos prévios e as observações experimentais, apenas uma das quais será a de aceitar os dados e alterar as concepções teóricas. Este fato tem enormes implicações para a estrutura de sequências didáticas para o ensino de Ciências. É necessário delinear estratégias adequadas para colocar " a cultura científica em estado de mobilização permanente, para substituir o saber estático e fechado pelo conhecimento aberto $e$ dinâmico... oferecer enfim à razão, razão para evoluir" (BACHELARD, 2013, p.24).

No presente trabalho, como a sequência didática explora conceitos iniciais da área de magnetismo, o foco de interesse é emergência da zona empírica, da "geometrização dos conceitos" (BACHELARD, 2013) de força e campo magnéticos, da definição de variáveis relevantes à experimentação, a partir da observação da "fenomenologia primeira", intuitiva, dos estudantes.

\section{Materiais e Métodos}

No curso do presente trabalho, desenvolveu-se um protótipo para atividade experimental, visando possibilitar a análise de simetria da força magnética. Desenvolveu-se uma sequência didática, com a construção dos conceitos básicos de propriedades magnéticas e campo magnético, que culmina com o uso do protótipo em uma atividade experimental quantitativa. Aplicou-se a sequência didática na escola e os registros e as atividades desenvolvidas pelos estudantes foram analisadas e categorizadas conforme as três etapas da metodologia de análise de conteúdo discutidas por Pádua (2002). Utilizando o perfil conceitual bachelardiano composto pelas zonas intuitiva, empírica e racional, indícios da evolução do perfil conceitual são estudados, qualitativamente, a partir dos achados da análise de conteúdo.

\footnotetext{
${ }^{2}$ O conceito de "Conflito Cognitivo" em Piaget possui as mesmas características fenomenológicas do conceito de "Dissonância Cognitiva" em Festinger. Veja McLeod, 2014.
} 


\section{IV.1 Protótipo experimental: a balança de Ampère-Faraday}

A força magnética aparece se cargas elétricas em movimento estão na presença de um campo magnético. Assim, uma carga $q_{o}$, movendo com velocidade $\vec{v}$ na presença de um campo magnético $\vec{B}$ ficará sujeita a uma força magnética:

$$
\overrightarrow{F_{M}}=q_{o} \vec{v} \times \vec{B} .
$$

A simetria da interação magnética é descrita matematicamente pelo produto vetorial $\vec{v} \times \vec{B}$. Isto significa que a direção da força é perpendicular ao plano definido pelos vetores $\vec{v}$ e $\vec{B}$. Como na matemática básica do ensino médio não se constrói o conceito de produto vetorial, a regra da mão direita é estabelecida na disciplina de física como regra mnemônica para tratar a questão de simetria envolvida. Vale ressaltar que, mais do que um dado experimental, a interação descrita pela eq. 1 é uma exigência de simetria.

Não é possível ver cargas elementares em movimento. Assim, a Eq. (1) se evidencia experimentalmente pela força magnética sobre um fio de comprimento L com corrente elétrica I,

$$
\overrightarrow{F_{M}}=\mathrm{IL} \times \vec{B}
$$

Visando a observação destas relações, o aparato experimental foi elaborado visando a permitir ao estudante investigar a direção da força magnética em função da configuração da corrente elétrica e do campo magnético. Um detalhamento da construção do aparato e da sequência didática pode ser obtido na dissertação (FERNANDES, 2015).

$\mathrm{O}$ arranjo experimental para medida da Força Magnética é fruto de uma análise da simetria de diferentes configurações, visando evidenciar a relação expressa pela eq. 1 . Inicialmente, a intenção era a de realizar medidas da força magnética gerada pelo campo magnético de um solenoide sobre uma espira. Entretanto, a intensidade do campo (tipicamente $B_{o} \approx 3 \cdot 10^{-2} T$ ) não gera força suficiente para a sensibilidade da balança eletrônica disponível. Além disto, o efeito espúrio relacionado a campos espalhados gera forças contrárias ao efeito que deseja-se medir. Na verdade, ao substituir o solenoide por ímãs de Neodímio, visando dispor de campo magnéticos de maior intensidade, observamos que a influência dos campos espalhados é ainda mais relevante. A questão fundamental é a de evitar seus efeitos indesejados. A Fig. 1 apresenta duas configurações inicialmente testadas. Uma espira em forma de $\mathbf{U}$, na horizontal (plano xoy), está na presença de um campo horizontal, a), e vertical, b), gerado por um ímã próximo à extremidade da espira. A espira é articulada por um eixo na outra extremidade, sendo sensível ao torque gerado por uma força vertical na extremidade próxima ao ímã. Note que os campos espalhado em ambas as configurações geram força nos braços laterais da espira. Na configuração a) as forças $\overrightarrow{F_{2}}$ e $\overrightarrow{F_{3}}$ são contrárias à força na extremidade $\left(\overrightarrow{F_{1}}\right)$, dificultando a medida do torque sobre a espira. 

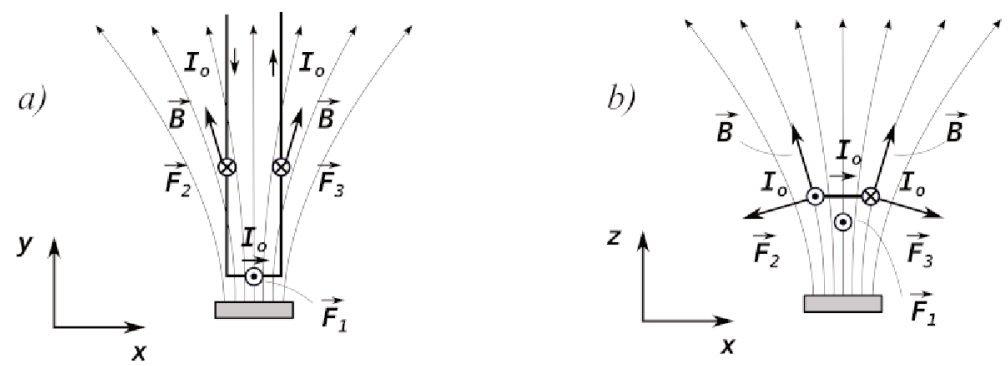

Fig. 1 - Efeito espúrio do campo espalhado sobre uma espira na horizontal nas configurações inicialmente testadas: a) campo na horizontal, direção oy e b) campo na vertical, direção oz.

Na configuração b) o campo está na vertical e a figura retrata a visão frontal da espira. Neste caso, a força $\overrightarrow{F_{1}}$ que atua na extremidade da espira é na horizontal, saindo do plano do papel, e não gera torque. Portanto, o aparato deveria acusar força magnética com componente vertical nula. Entretanto, os campos espalhados geram as forças $\overrightarrow{F_{2}}$ e $\overrightarrow{F_{3}}$ com ligeira inclinação, gerando componentes verticais que são detectadas pelo aparato. Este é o caso mais grave do ponto de vista didático, pois esperar-se-ia um torque nulo na espira e a observação de um torque, mesmo que residual, dificulta a compreensão da simetria da interação magnética pelo estudante.
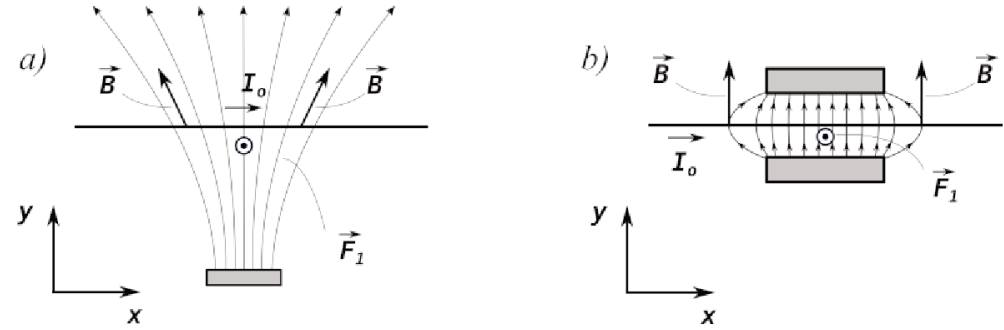

Fig. 2 - Configuração utilizando um fio reto longo na extremidade da espira, com um ímã, a), e com dois ímãs em forma de U (visão frontal), b). Embora os campos espalhados próximos ao ímã não causem efeitos indesejados, apenas a configuração b) com o campo magnético confinado a uma região próxima aos ímãs é livre dos efeitos espúrios dos campos espalhados.

Para contornar essa dificuldade, optou-se por testar uma espira larga, de forma que a região onde o campo magnético atua fosse um fio reto e longo, longe da parte lateral da espira. Nesta configuração (Fig. 2, configuração a), os campos espalhados próximos ao ímã têm componentes paralelas à direção da corrente, não gerando, portanto, força magnética. Entretanto, longe do ímã, as linhas de campo retornam gerando uma força oposta à força $\overrightarrow{F_{1}}$.

Entretanto, a configuração com maior clareza didática é, portanto, a configuração 2 b). Neste caso, posicionam-se dois ímãs com polos opostos em um suporte de ferro doce ou 
ferrita em forma de U. Nesta configuração, o campo magnético é uniforme na região entre os polos dos ímãs e a intensidade e a direção são constantes na região central. Devido à simetria dos ímãs no suporte em U, as linhas de campo retornam pelo suporte, não gerando, assim, os efeitos espúrios. Além disto, observa-se que a intensidade do campo magnético cai a valores menores que $10 \%$ a uma distância de alguns milímetros da borda do ímã. Desta forma, podese estimar o comprimento do fio que está sujeito à ação do campo magnético como sendo aproximadamente igual ao comprimento do ímã.

A Fig. 3 apresenta uma imagem da versão final da balança de Ampère-Faraday construída. O produto educacional, com detalhes sobre o desenvolvimento, construção e funcionamento deste protótipo, bem como do planejamento da Sequência Didática proposta está disponível sob o título: "Balança de Ampère-Faraday: uma estratégia para discutir campo magnético e força magnética" em <http://www1.fisica.org.br/mnpef/?q=defesas\%2Fprodutos \&field_polo_value=12>.

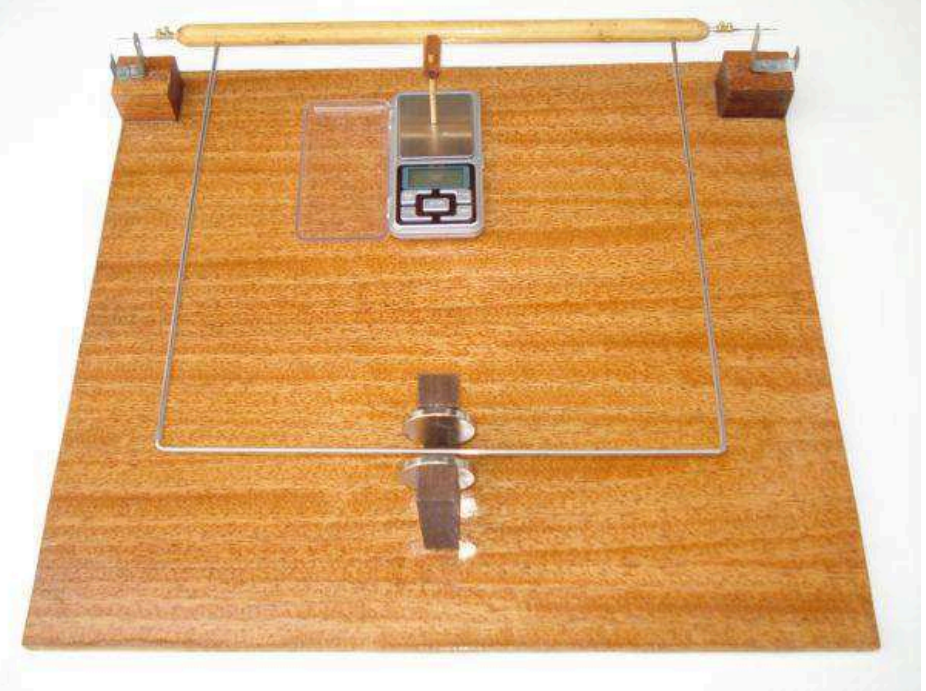

Fig. 3 - Versão final do aparato. Uma espira em forma de U fica sujeita à força magnética na parte do fio reto e longo numa extremidade da espira. A outra extremidade é articulada em um eixo de madeira, de forma que o torque gerado pela componente vertical da força magnética pode ser medido diretamente em uma mini balança eletrônica.

\section{IV.2 Proposta didática}

Diversas abordagens metodológicas do tipo "active learning" buscam fomentar o surgimento do conflito cognitivo na sequência didática como estratégia didática (HENRIQUES; PRADO; VIEIRA, 2014; SOKOLOFF; THORNTON, 1997). Geralmente solicita-se ao aluno externar suas previsões sobre eventos específicos do tema em estudo, em situações 
em que as concepções do senso comum (zona intuitiva), não contemplam a complexidade do fenômeno em estudo.

Neste sentido, o desenvolvimento da sequência didática para o estudo do campo magnético e interações magnéticas foi norteado pela busca do estabelecimento de dois conflitos cognitivos básicos: (i) destacar as incoerências e inadequações da analogia entre campo elétrico e campo magnético, propriedades elétricas e propriedades magnéticas; (ii) evidenciar o comportamento de simetria da força magnética ligado ao produto vetorial do campo magnético. Na tabela 1 apresentamos os tópicos, a formulação do questionamento pretendido, bem como os conflitos cognitivos esperados.

Tabela 1 - Lista dos tópicos, questionamentos e conflitos cognitivos esperados que compõem a sequência didática sobre Campo Magnético e Força magnética.

\begin{tabular}{|c|c|c|c|}
\hline Tema & Roteiro & Questionamento & Conflito cognitivo esperado \\
\hline $\begin{array}{l}\text { Materiais } \\
\text { magnéticos }\end{array}$ & I & $\begin{array}{l}\text { 1. Qual o efeito do ímã sobre os } \\
\text { diferentes materiais? }\end{array}$ & $\begin{array}{l}\text { Nem todo material condutor elé- } \\
\text { trico, metálico, tem propriedades } \\
\text { magnéticas }\end{array}$ \\
\hline $\begin{array}{l}\text { Linhas de } \\
\text { campo mag- } \\
\text { nético }\end{array}$ & II & $\begin{array}{l}\text { 2. Qual é a forma das linhas de } \\
\text { campo magnético dos ímãs } \\
\text { disponibilizados? }\end{array}$ & $\begin{array}{l}\text { Limites do conceito de força não } \\
\text { dão conta da complexidade da } \\
\text { distribuição das linhas de campo } \\
\text { magnético. }\end{array}$ \\
\hline $\begin{array}{l}\text { Sentido do } \\
\text { campo mag- } \\
\text { nético }\end{array}$ & III & $\begin{array}{l}\text { 3. Qual o efeito de um ímã so- } \\
\text { bre a agulha de uma bússola? } \\
\text { Revendo seu desenho das li- } \\
\text { nhas de campo, qual o sentido } \\
\text { do campo em cada situação } \\
\text { analisada? }\end{array}$ & $\begin{array}{l}\text { Carácter vetorial do campo mag- } \\
\text { nético. O aluno deve, inicialmen- } \\
\text { te, identificar o sentido de orienta- } \\
\text { ção da bússola com o sentido do } \\
\text { vetor campo magnético. }\end{array}$ \\
\hline \multirow{4}{*}{$\begin{array}{l}\text { Força magné- } \\
\text { tica sobre } \\
\text { correntes }\end{array}$} & \multirow{4}{*}{ IV e $\mathrm{V}$} & $\begin{array}{l}\text { 4. Qual a relação entre a força } \\
\text { magnética e a direção da cor- } \\
\text { rente elétrica no fio? }\end{array}$ & $\begin{array}{l}\text { A força é perpendicular à direção } \\
\text { da corrente. }\end{array}$ \\
\hline & & $\begin{array}{l}\text { 5. Qual a relação entre a força } \\
\text { magnética e a corrente? }\end{array}$ & $\begin{array}{l}\text { Relação linear como resultado } \\
\text { experimental }\end{array}$ \\
\hline & & $\begin{array}{l}\text { 6. Qual é a relação entre a força } \\
\text { magnética e a direção do cam- } \\
\text { po magnético? }\end{array}$ & $\begin{array}{l}\text { A força é perpendicular ao campo. } \\
\text { As linhas de campo não são linhas } \\
\text { de força. }\end{array}$ \\
\hline & & $\begin{array}{l}\text { 7. Qual o efeito do campo } \\
\text { magnético sobre um fio com } \\
\text { uma corrente elétrica na hori- } \\
\text { zontal nas configurações } \mathbf{A} \\
\text { (Campo na vertical) e B (cam- } \\
\text { po na horizontal)? }\end{array}$ & $\begin{array}{l}\text { A força magnética que atua sobre } \\
\text { um fio com corrente elétrica não é } \\
\text { ao longo da direção do campo } \\
\text { magnético. }\end{array}$ \\
\hline
\end{tabular}


O desenvolvimento da sequência didática envolveu, portanto, a implementação de atividades em grupo, problematizando os tópicos apresentados na tabela 1, como uma atividade de laboratório estruturada.

\section{Aplicação da sequência didática e resultados}

A SD foi ministrada a uma turma de quarenta estudantes do terceiro ano do ensino médio em uma escola pública estadual do sul de Minas Gerais durante o final do ano de 2014. Nas aulas anteriores à aplicação da SD, foi desenvolvido junto aos estudantes o currículo tradicional, consistindo dos tópicos de eletrostática e corrente elétrica: carga elétrica, força elétrica, campo elétrico, condutores e isolantes, corrente elétrica e circuitos resistivos simples. Os estudantes foram informados de que se tratava de uma SD experimental, como parte do desenvolvimento de uma dissertação de mestrado profissional e deram a sua anuência à participação no processo com certa curiosidade e interesse.

Os roteiros das atividades constavam de duas etapas. Inicialmente, em cada atividade, os estudantes foram colocados diante de uma questão e deveriam registrar suas previsões iniciais. Este registro era entregue ao professor. Na etapa seguinte os estudantes realizam os experimentos propostos e recebem uma nova ficha de registro para o registro das observações após a realização dos experimentos. As fichas de registro foram analisadas e as respostas categorizadas visando identificar eventuais evoluções no perfil conceitual dos estudantes.

\section{V.1 Análise do roteiro de atividade I - Materiais magnéticos}

Nesse roteiro o tema é Materiais Magnéticos. O objetivo pedagógico consiste em reconhecer os tipos de materiais e o efeito de um ímã sobre eles. Na ficha de questionamento e previsão de resultados, confronta-se o estudante com a situação-problema de prever e verificar o comportamento magnético de diferentes materiais. Em especial, a lista apresenta diferentes metais, visando a percepção de que nem todo metal é magnético, embora todos sejam condutores. A ficha deste roteiro consiste basicamente em uma lista de materiais. Especificamente, o estudante deveria responder à seguinte questão: Se você aproximar um ímã de cada um desses materiais, qual seria o efeito observado? Pede-se que os grupos anotem suas previsões iniciais e as justificativas.

As fichas de previsão foram entregues ao professor e os alunos receberam a seguir os materiais para desenvolvimento experimental da atividade. Ao testar o efeito de um ímã sobre os materiais disponibilizados, os estudantes devem registrar suas observações e apresentar uma justificativa. 
Tabela 2 - Observações das etapas 1.1 e 1.2 do roteiro de atividades I.

\begin{tabular}{|c|c|c|}
\hline Grupo & $\begin{array}{l}\text { 1.1 Previsão - Antes de reali- } \\
\text { zar o experimento }\end{array}$ & $\begin{array}{l}\text { 1.2 Observação - Após realização do experi- } \\
\text { mento }\end{array}$ \\
\hline G1 & $\begin{array}{l}\text { Todos os metais são atraídos } \\
\text { pelos ímãs. Justifica: "Gruda, } \\
\text { porque é metal" }\end{array}$ & $\begin{array}{l}\text { Identifica corretamente quando há atração/não há } \\
\text { atração. } \\
\text { Entretanto apresenta explicação tautológica, do } \\
\text { tipo "Gruda, porque há atração" e "Não gruda, } \\
\text { porque não há atração". }\end{array}$ \\
\hline G2 & $\begin{array}{l}\text { Afirma que os elétrons possuem } \\
\text { cargas positivas e negativas } \\
\text { (sic), iguais ou diferentes, e estas } \\
\text { cargas dão origem ao compor- } \\
\text { tamento magnético. }\end{array}$ & $\begin{array}{l}\text { Identifica corretamente quando há atração/não há } \\
\text { atração. } \\
\text { Entretanto apresenta explicação relacionando } \\
\text { atração devido a cargas iguais, e a não-atração } \\
\text { com cargas diferentes. }\end{array}$ \\
\hline G3 & $\begin{array}{l}\text { Todos os materiais são atraídos } \\
\text { pelos ímãs. }\end{array}$ & $\begin{array}{l}\text { Identifica corretamente quando há atração/não há } \\
\text { atração. } \\
\text { Entretanto apresenta explicação desconectada, } \\
\text { relacionando forças opostas x magnetismo. }\end{array}$ \\
\hline G4 & $\begin{array}{l}\text { Diferencia cobre e alumínio, } \\
\text { mas não apresenta modelo expli- } \\
\text { cativo. }\end{array}$ & $\begin{array}{l}\text { Identifica corretamente quando há atração/não há } \\
\text { atração. } \\
\text { Entretanto apresenta explicação tautológica, } \\
\text { "atrai por que é atraído". }\end{array}$ \\
\hline G5 & $\begin{array}{l}\text { Diferencia cobre e alumínio co- } \\
\text { mo não magnéticos, e cria a } \\
\text { classe dos materiais não ferro- } \\
\text { sos. }\end{array}$ & $\begin{array}{l}\text { Identifica corretamente quando há atração/não há } \\
\text { atração. } \\
\text { Entretanto cria a classe dos ferrosos e não ferro- } \\
\text { sos. Para o níquel apresenta a explicação "tem } \\
\text { propriedades magnéticas", o que representa a } \\
\text { chave para interpretar o impasse de que nem to- } \\
\text { dos os materiais magnéticos possuem ferro. }\end{array}$ \\
\hline
\end{tabular}

A tabela II apresenta a categorização das respostas apresentadas nas etapas Previsão (1.1) e de Observação (1.2) dessa atividade I. Note que o grupo G3 apresenta a hipótese ingênua de que todos os materiais são atraídos por um ímã, e o grupo G1, de que todos os metais são atraídos pelo ímã. Após a realização do experimento, estes grupos são confrontados com o dado empírico de que nem todos os materiais apresentam interação magnética. Na busca de conciliar as duas posições, o grupo G1 apresenta um raciocínio tautológico, "gruda por que há atração" e "não gruda por que não há atração" Entretanto, com relação ao metal alumínio, o mesmo grupo G1 apresenta uma explicação interessante: "Não acontece nada, pois não há eletromagnetismo no alumínio", identificando, portanto, que este metal tem comportamento magnético distinto. O grupo G3 se perde em tentativas de explicação desconectadas. De uma forma análoga, os grupos G4 e G5 diferenciam os metais alumínio e cobre, mesmo antes 
do experimento. Entretanto, se perdem em explicações tautológicas e não são capazes de identificar a constatação simples de que nem todo metal apresenta interação magnética. Digno de nota é a criação da classe de materiais ferrosos pelo grupo G5, pois significa uma tentativa de criar categorias, ainda que dentro de uma concepção "substancialista" conforme Bachelard. Por outro lado, esta é a resposta que mais coaduna com a constatação empírica proposta pela atividade, de que diferentes materiais têm diferentes comportamentos magnéticos. Como ferro é o metal magnético mais amplamente conhecido, passa assim a ser um emblema para a categorização. Daí compreendermos a dificuldade do grupo em classificar o níquel presente nas moedas como material ferroso. Assim, a conclusão do grupo G5 de que o níquel "tem propriedades magnéticas" foi a tentativa de resolver o impasse de que nem todos os materiais magnéticos possuem ferro.

O Grupo G2 apresenta uma confusão entre os conceitos de eletricidade e magnetismo que tem sido observado com frequência em outros estudos (SCAIFE e HECKLER, 2010 e 2011; FURIÕ e GUISASOLA, 1998). Voltaremos a este tema nas discussões.

\section{V.2 Análise do roteiro de atividade II - Linhas de Campo Magnético}

No segundo roteiro, explora-se um experimento corriqueiro nas aulas de Ciências e de Física Básica, o da visualização do campo magnético utilizando limalhas de ferro. Entretanto, o desafio consiste em que os grupos antecipem o resultado da distribuição da limalha no espaço entre os ímãs em três situações diferentes: (i) um único ímã; (ii) dois ímãs com polos opostos voltados um para o outro; (iii) mesmos polos voltados um para o outro. A tabela 3 apresenta a categorização das observações.

De uma forma geral, as previsões dos grupos foram confusas e desconectadas, mesmo após a realização do experimento. Vale, entretanto, ressaltar que o G1 apresenta grande evolução em relação ao comportamento na atividade 1, apresentando um perfil conceitual que avança na zona empírica. Um indicativo é que o grupo se coloca a questão sobre se a interação magnética atravessaria a placa de acrílico. Esse fato é ainda corroborado pela observação de sua atitude investigativa demonstrada na fase de observação empírica. Foi o grupo que apresentou uma abordagem mais sistemática na observação experimental. Vale ressaltar que o grupo G2 aparentemente persiste com dificuldades na compreensão do conceito de campo. Assim, suas respostas são balizadas pela visão de "ação a distância” entre os ímãs, não percebendo o papel da limalha como sensor para evidenciar o campo magnético. Como observado na literatura, este é um fator que dificulta a diferenciação entre o comportamento magnético e elétrico (SCAIFE e HECKLER, 2010).

Observa-se ainda que o grupo G3, apesar de apresentar-se confuso na busca por explicações, foi o grupo que conseguiu sintetizar de forma mais clara as observações no desenho esquemático das linhas de campo. 
Tabela 3 - Observações das etapas 2.1 e 2.2 do roteiro de atividades II.

\begin{tabular}{|l|l|l|}
\hline Grupo & $\begin{array}{l}\text { 2.1 Previsão - Antes de realizar o } \\
\text { experimento }\end{array}$ & $\begin{array}{l}\text { 2.2 Observação - Após realização do ex- } \\
\text { perimento }\end{array}$ \\
\hline G1 & $\begin{array}{l}\text { Afirma que existe interação através } \\
\text { do acrílico, e que a configuração do } \\
\text { ímã vai alterar a da limalha. }\end{array}$ & $\begin{array}{l}\text { 1) Observa as linhas de campo;2) Desenha as } \\
\text { linhas; 3) É coerente na observação da distri- } \\
\text { buição de limalhas; 4) Modelo ou concepção } \\
\text { simples de "ação a distância", } \\
\text { Atrai/não atrai. }\end{array}$ \\
\hline G2 & $\begin{array}{l}\text { Responde de forma confusa, sem } \\
\text { deixar claro se fala do ímã ou da da } \\
\text { limalha. }\end{array}$ & $\begin{array}{l}\text { 1) Observa as linhas mas 2) persiste em focar } \\
\text { apenas a interação a distância entre os ímãs. }\end{array}$ \\
\hline G3 & $\begin{array}{l}\text { Afirma, de forma incompreensível, } \\
\text { que "Um ímã não se agrupa e com } \\
\text { dois se atrai". }\end{array}$ & $\begin{array}{l}\text { Observa e faz um desenho coerente com as } \\
\text { observações, sem apresentar reflexões sobre } \\
\text { elas. }\end{array}$ \\
\hline G4 & $\begin{array}{l}\text { Sem conexão com as linhas de cam- } \\
\text { po, afirma que o acrílico vai interfe- } \\
\text { rir. }\end{array}$ & $\begin{array}{l}\text { Respostas desconectada da pergunta propos- } \\
\text { ta. }\end{array}$ \\
\hline Gem conexão com as linhas de cam- \\
po.
\end{tabular}

Vale ressaltar que as dificuldades encontradas pelos estudantes neste experimento são compreensíveis e, de certa forma, esperadas. Ao utilizar limalha de ferro como sensor para o campo magnético, é natural esperar que os estudantes, em primeira linha, esperem que a limalha seja atraída pelos polos do ímã. Inusitado para os estudantes é constatar que a certa distância dos polos a limalha se oriente no espaço evidenciando a presença de um campo magnético. Note que, dada a característica tradicional do ensino na realidade da escola pública brasileira, esta foi a primeira vez em que os estudantes foram confrontados com uma evidência experimental da existência de um campo. Mas esta é exatamente a virtude da atividade proposta: tornar mais concreto o conceito abstrato de campo.

\section{V.3 Análise do roteiro de atividade III - Direção do Campo Magnético}

O terceiro roteiro tem por objetivo a construção do conceito de campo magnético como um vetor. Visa, portanto, problematizar a questão do sentido que deve ser associado às linhas de campo observadas na etapa anterior.

Assim, as questões do roteiro nesta etapa são: "Qual o efeito de um ímã sobre a agulha de uma bússola? Revendo o seu desenho das linhas de campo, qual o sentido do campo 
em cada situação analisada?". A Fig. 4 apresenta a questão de investigação neste roteiro e a tabela 4, a categorização das observações.

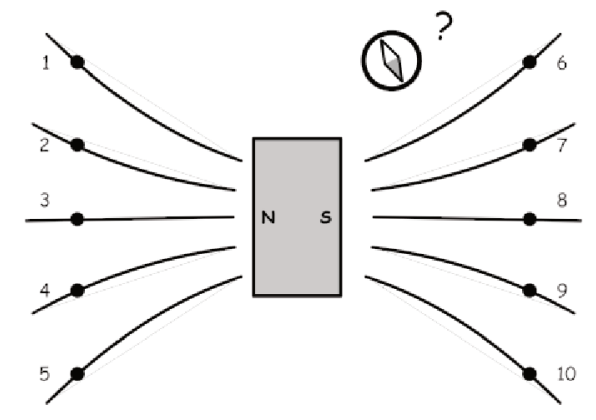

Fig. 4 - Questão do roteiro 3: "O sentido das linhas do campo magnético pode ser revelado usando uma bússola. Faça uma previsão do resultado e uma representação gráfica do que você espera observar quando você colocar uma bússola nos pontos $(1-10)$ próximos de um imã?"

Tabela 4 - Observações das etapas 3.1 e 3.2 do roteiro de atividades III.

\begin{tabular}{|c|c|c|}
\hline Grupo & $\begin{array}{l}\text { 3.1 Previsão - Antes de realizar o } \\
\text { experimento }\end{array}$ & $\begin{array}{l}\text { 3.2 Observação - Após realização do ex- } \\
\text { perimento }\end{array}$ \\
\hline G1 & $\begin{array}{l}\text { Sem noção de direção da agulha } \\
\text { magnética em relação ao ímã. }\end{array}$ & $\begin{array}{l}\text { Passou para o desenho o que observou na } \\
\text { agulha da bússola, agulha na direção certa. }\end{array}$ \\
\hline $\mathrm{G} 2$ & Confusão com campo elétrico. & $\begin{array}{l}\text { Passou para o desenho o que observou na } \\
\text { agulha da bússola, agulha na direção certa. }\end{array}$ \\
\hline G3 & $\begin{array}{l}\text { Já tinham noção da direção da agu- } \\
\text { lha em relação ao campo. Previsão } \\
\text { correta. }\end{array}$ & $\begin{array}{l}\text { Confirmou a previsão proposta na primeira } \\
\text { etapa. }\end{array}$ \\
\hline G4 & $\begin{array}{l}\text { Raciocínio confuso, não têm noção } \\
\text { do que é uma bússola. }\end{array}$ & $\begin{array}{l}\text { O grupo não conseguiu esclarecer o que foi } \\
\text { observado. }\end{array}$ \\
\hline G5 & $\begin{array}{l}\text { Já tinham noção da direção da agu- } \\
\text { lha em relação ao campo. Previsão } \\
\text { correta. }\end{array}$ & $\begin{array}{l}\text { Confirmou a previsão proposta na primeira } \\
\text { etapa. }\end{array}$ \\
\hline
\end{tabular}

Nesta etapa, o grupo G2 permanece confuso em relação à diferenciação entre comportamento elétrico e comportamento magnético, demonstrando a persistência da dificuldade epistemológica e conceitual em absorver o conceito de interação magnética, quando se constrói o conceito a partir de analogias com a interação elétrica. Apesar deste fato, realiza a atividade proposta de forma correta e apresenta corretamente os resultados empíricos. Note ainda que os grupos G1 e G4 estão confusos, aparentemente por não compreenderem o que é uma 
bússola. Os grupos G3 e G5, ao contrário, aparentemente possuem conhecimento prévio do experimento.

Após a realização da etapa experimental, exceto o G4, todos os outros grupos observam corretamente a direção e o sentido do campo magnético como evidenciado pela bússola. Entretanto, os dados de observação não permitem uma investigação mais profunda sobre a interpretação dos estudantes e as respectivas concepções.

\section{V.4 Análise do roteiro de atividade IV - Simetria da interação magnética}

O quarto roteiro visa discutir a simetria da força magnética, numa realização da famosa experiência de Oersted. O roteiro consta de três configurações apresentadas nas figura 3 -5 abaixo. A questão apresentada foi:

Roteiro IV ...Imagine um condutor elétrico percorrido por uma corrente elétrica na presença de campo magnético. Que tipo de interação pode ocorrer? Considerando as três configurações abaixo, explique com desenhos a direção do campo magnético e represente a força magnética por seta, em cada caso. (FERNANDES, 2015, P. 123)

Os estudantes são questionados sobre a força de interação entre o campo e cargas em movimento em uma corrente elétrica. No roteiro, apresentam-se três configurações do campo magnético: (i) na horizontal e paralelo à corrente, (ii) perpendicular à corrente na vertical e (iii) perpendicular à corrente na horizontal.

Tabela 5 - Observações das etapas 4.1 e 4.2 do roteiro de atividades IV.

\begin{tabular}{|c|l|l|}
\hline Grupo & $\begin{array}{l}\text { 3.1 Previsão - Antes de realizar o } \\
\text { experimento }\end{array}$ & $\begin{array}{l}\text { 3.2 Observação - Após realização do } \\
\text { experimento }\end{array}$ \\
\hline G1 & $\begin{array}{l}\text { Na primeira configuração respondeu } \\
\text { correto, na segunda e terceira sem coe- } \\
\text { rência. }\end{array}$ & $\begin{array}{l}\text { Observou o experimento, não soube inter- } \\
\text { pretar. }\end{array}$ \\
\hline G2 & $\begin{array}{l}\text { Não tem relação com a questão e afir- } \\
\text { ma que ímã atrairá a corrente. }\end{array}$ & $\begin{array}{l}\text { Não conseguiu identificar a direção na } \\
\text { observação do experimento, mas concluiu } \\
\text { que é de 90 graus. }\end{array}$ \\
\hline G3 & $\begin{array}{l}\text { Resposta sem sentido. } \\
\text { Observou e não interpretou adequadamen- } \\
\text { te o experimento. }\end{array}$ \\
\hline G4 & $\begin{array}{l}\text { Confunde faísca nos contatos com atra- } \\
\text { ção. }\end{array}$ & $\begin{array}{l}\text { Observou a direção da força magnética, } \\
\text { mas afirma que a corrente atrai campo. }\end{array}$ \\
\hline G5 & $\begin{array}{l}\text { Sem noção de força. } \\
\text { Observou o sentido da força e concluiu } \\
\text { corretamente que a relação é de 90 graus. }\end{array}$ \\
\hline
\end{tabular}

Dada a dificuldade de visualização da orientação dos ímãs em relação ao fio em três dimensões, uma discussão prévia com os estudantes procurou esclarecer as dúvidas para se ter 
certeza que eles compreenderam corretamente o comando e as configurações propostas. $\mathrm{Na}$ tabela 5 apresentamos a categorização dos resultados. Inicialmente, como era de se esperar, ao trazer uma questão nova sobre um fenômeno completamente desconhecido aos estudantes, a discussão na primeira etapa do roteiro, em que envolvia uma previsão de resultados, foi muito errática. Apenas dois grupos, G1 e G2, aventaram a possibilidade de aparecer uma força pela interação entre a corrente e o campo magnético, sinalizando para a não diferenciação entre a interação elétrica e a magnética.

Na etapa de observação, os estudantes utilizaram a Balança de Ampére-Faraday (figura 3) para fazer observações qualitativas acerca das direções relativas do campo, corrente e força magnética. Apesar de estarem tendo um primeiro contato com o fenômeno, todos os grupos foram capazes de observar o efeito do campo magnético sobre a corrente elétrica de forma qualitativamente correta. Entretanto, apresentaram dificuldades em sua interpretação. Apenas dois grupos, G2 e G5, foram capazes de identificar a questão crucial de simetria da interação magnética: o ângulo de noventa graus entre o campo magnético e a força magnética. Durante as discussões que se seguiram à apresentação dos resultados, o professor-pesquisador apresentou a regra da mão direita como síntese da observação empírica realizada pelos estudantes de que a força magnética atua perpendicularmente ao campo magnético e à direção da corrente elétrica no fio.

Vale ressaltar que nas configurações (1) e (2) escolhidas, o campo magnético gerado pelos polos do ímã em U na extremidade do fio (figura 3), são colocados na vertical e na horizontal, respectivamente. Na configuração (3) o campo está paralelo à corrente. Assim, nas duas primeiras configurações o campo magnético é perpendicular à corrente em ambos os casos. Mas na configuração (1) em que as linhas do campo magnético estão na vertical, a força magnética não gera torque no aparato e a balança eletrônico mede zero, ao passo que na configuração (2), campo na horizontal, a força magnética gera torque, o que é evidenciado pela medida na balança. Estas configurações foram utilizadas para uma discussão qualitativa da regra da mão direita e para o fato de que o valor da força magnética varia com o ângulo entre o campo e a corrente de acordo com o seno do ângulo.

Destaca-se o registro do grupo G4 sobre suas observações nas três diferentes configurações: "Estava quase certo a primeira, só não sabíamos o sentido da força resultante do campo no polo N/S. Na segunda houve surpresa a saber que a força seria para cima e para baixo. Na terceira imaginávamos que iria se anular em parte, mas anulou por completo". A surpresa na segunda configuração se dá exatamente por se constatar que a força não está na direção do campo!

\section{V.5 Análise do roteiro de atividade V - Balança de Ampère-Faraday}

O último roteiro da sequência didática visa a realização da medida experimental da intensidade da força magnética sobre um condutor percorrido por uma corrente elétrica, variando a corrente elétrica. Os estudantes são orientados a utilizar o protótipo experimental para 
a realização das medidas. Os dados são inseridos em uma tabela e transpostos para um gráfico em papel milimetrado.

A medida da força magnética na montagem experimental utilizada é realizada pela leitura de uma mini balança eletrônica. A balança mede a força em "gramas". Além disto, a razão entre os braços de alavanca introduz um fator multiplicativo de 10 na força aplicada à balança. Em discussão prévia com os estudantes, o professor problematiza estas questões para determinar a constante de calibração que permita expressar a força em unidades do Sistema Internacional SI. Assim, os estudantes podem gerar gráficos de medida quantitativamente correta.

Apresentamos na Fig. 4 os resultados experimentais do grupo G4. O gráfico foi realizado pelo professor a partir da tabela de medidas dos estudantes.

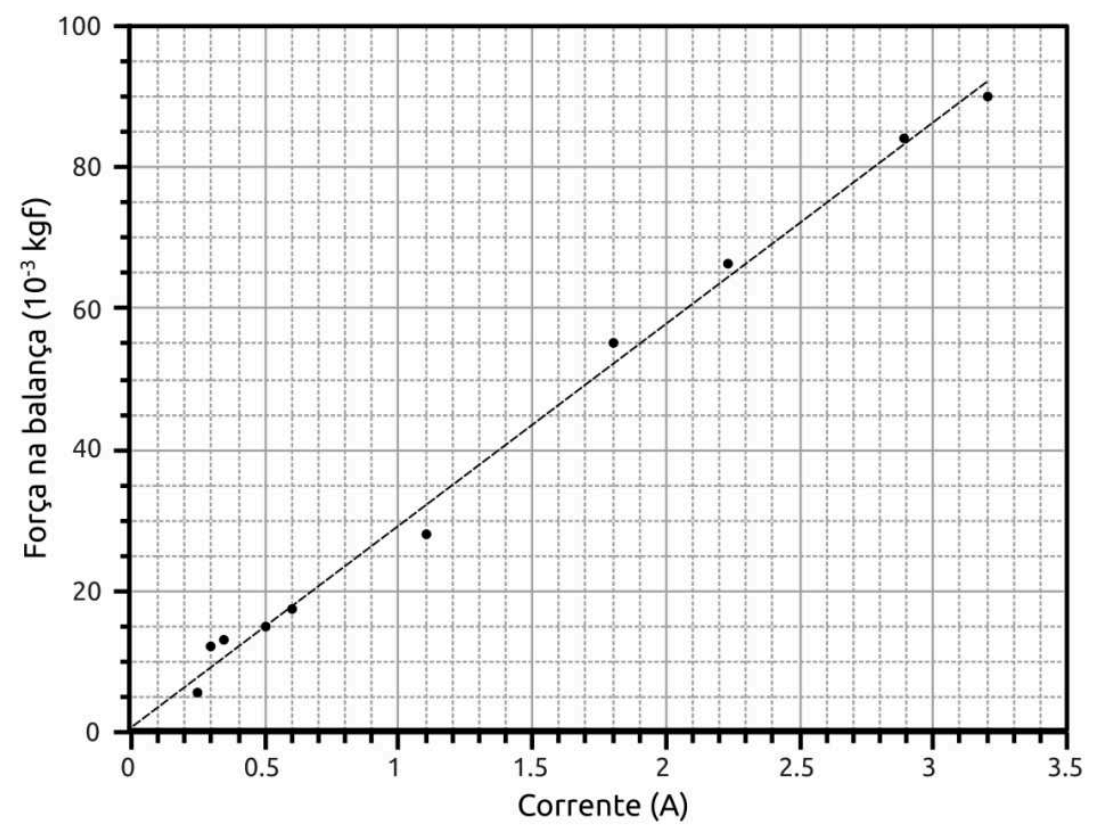

Fig. 4 - Gráfico elaborado a partir dos resultados experimentais do grupo G4 obtidos na realização da atividade $V$ utilizando o aparato desenvolvido (Fig. 3).

Todos os grupos foram capazes de realizar todas as etapas da atividade experimental proposta. Apenas dois grupos não foram capazes de construir o gráfico da força pela corrente. Em uma das questões do roteiro, explora-se novamente a questão de simetria da força magnética. Os estudantes são orientados a realizar a medida com o campo na vertical e comparar com a medida anterior, realizada com o campo na horizontal. Todos os grupos foram capazes de observar que nesta configuração a força magnética não gera torque e não pressiona a mini balança. A dramática diferença entre as medidas nas duas configurações propostas teve o efeito desejado de gerar o debate. Na configuração com campo na horizontal, o grupo G4 realizou as medidas apresentadas na Fig. 4. Realizaram três medidas na configuração com campo na vertical, aplicando correntes de $0,6 \mathrm{~A}, 1,84 \mathrm{~A}$ e $3,2 \mathrm{~A}$, tendo detectado o resultado nulo. $\mathrm{E}$ 
conseguem identificar corretamente que o resultado é devido à direção do campo, "O campo força (sic) está para baixo então não irá chegar a balança para medir". Os grupos G1 e G2 identificaram de forma mais clara: "A força vai ser zero sobre a balança, porque a força não é para baixo". Apenas o grupo G5 esteve apático, observou que o campo na vertical fornece um resultado nulo, mas não forneceu nenhuma resposta às questões.

Assim, concluímos que os grupos identificam corretamente a simetria da interação magnética, embora esta constatação não aparente ter sido internalizada em suas relações teóricas mais profundas.

\section{Discussão}

Mais do que a eventual constatação da fragilidade conceitual do grupo de estudantes analisado, os fatos empíricos revelados pelas observações do grupo em estudo devem, necessariamente, ser interpretados em sua significação epistemológica.

Por um lado, as observações de diário de campo nos permitem coletar evidências de que o conflito cognitivo criado pela observação experimental não gera no estudante o mesmo grau de angústia de cometer erros em um exercício ou uma questão teórica. O que observamos foi, ao contrário, a surpresa e a curiosidade para compreender os fatos observados. No dizer do professor aplicador, os alunos ficaram entusiasmados com a proposta:

$O$ roteiro $V$ foi o mais participativo, todos grupos realizaram as medidas, fizeram os cálculos das forças correspondentes, embora tenham mostrando que tiveram dificuldade para elaborar a conclusão. (FERNADES, 2015, p. 109).

Entretanto, apesar do conflito cognitivo criar esta busca por uma compreensão do fenômeno, fomentando a busca pela acomodação da observação na estrutura cognitiva prévia, ele, por si só, não causa necessariamente um avanço da racionalização e na integração conceitual, não causa necessariamente a expansão das zonas do perfil conceitual relacionadas aos modos científicos de pensar. Com isto, predomina a busca por explicações tautológicas ou desconectadas.

Um avanço tênue no perfil conceitual pode ser observado pela tentativa de gerar uma classificação. Ao introduzir a classe de "materiais ferrosos" como modelo explicativo, o grupo G5 está próximo da conclusão básica que se pode tirar do experimento, que é a existência de diferentes comportamentos magnéticos dependendo do material. Cabe então ao professor orientar a discussão, problematizando o termo "ferrosos", talvez devido à identificação do comportamento magnético com o comportamento de um ímã de ferrita.

As principais concepções apresentadas pelos estudantes na fase de questionamento e previsão de resultados demonstram forte ancoragem do modo de pensar dos estudantes na zona intuitiva como descrito por Mortimer (EL-HANI et al., 2015). Evidencia-se aqui o que Bachelard descreve como obstáculo epistemológico criado pela "experiência primeira". A busca de generalização do conceito (ingenuamente) aprendido gera os obstáculos epistemológicos que impedem, ou dificultam, a evolução do processo de aprendizagem. Assim, observa- 
se neste estudo que a aprendizagem mecânica, não-crítica, da interação elétrica, cria obstáculos à aprendizagem da interação magnética.

Esta observação está de acordo com a literatura. Entretanto, o efeito inverso também tem sido relatado. Scaife e Heckler (2011) reportam sobre a emergência de erros conceituais na compreensão de força elétrica após o ensino de força magnética. Eles observaram que estudantes respondem incorretamente questões relacionadas à força elétrica, apresentando-a como perpendicular ao campo elétrico, após o estudo de força magnética. Isto evidencia um efeito de memória de curto prazo.

Outro obstáculo epistemológico observado foi o conceito de força magnética, como "ação a distância" entre objetos magnéticos, entre os polos dos ímãs, dificultando a compreensão do conceito de campo magnético. Este resultado corrobora Furió e Guisasola (1998) ao identificarem as dificuldades que o perfil conceitual coulombiano gera ao desenvolvimento do perfil maxwelliano no contexto do ensino de campo elétrico. Como observam estes autores, existem sérias "dificuldades de natureza ontológicas e epistemológicas na aplicação do conceito de campo". Sendo força um conceito de "experiência primeira", não é de se estranhar seu poder de dificultar uma aprendizagem posterior, o conceito de campo. Assim, apesar do apelo pictórico do experimento da limalha, seção V.2, persiste a dificuldade de amadurecimento do conceito de campo.

Ao afirmar que a "força é um conceito derivado de 'experiência primeira" não estamos nos referindo à complexa elaboração epistemológica de ação instantânea a distância, mas simplesmente ao conceito elementar de força, construído a partir dos sentidos, desde o primeiro empurrão. Assim, entendemos que o aprendizado primeiro em magnetismo é a constatação de que um ímã atrai outro ímã. Portanto, identificar a ideia de que um ímã gera um campo em todo o espaço e que o segundo ímã está sujeito aos efeitos deste campo é um conhecimento posterior que tem no primeiro conhecimento um obstáculo epistemológico. Esta constatação está também em Furió e Guasasola, na identificação das zonas coulombiana e maxwelliana

Nossas observações estão de acordo também com as dificuldades de aprendizagem da interação magnética em relação à aplicação da regra da mão direita (KUSTUSCH, 2016). Surpreendentemente, não foi observada explicitamente a concepção errônea - esperada pelos autores - de se prever uma força magnética paralela à direção do campo magnético. Nossos estudos não foram conclusivos sobre este ponto. Entretanto, a constatação de que apenas dois grupos foram capazes de explicitar a observação de que a direção da força magnética é perpendicular à direção do campo magnético - questão fundamental na compreensão da regra da mão direita -, é um indício de que esta concepção errônea está presente, ainda que latente.

Concluindo, a sequência didática proposta possibilita a problematização das questões relacionadas ao comportamento magnético de materiais e à simetria da interação do campo magnético com a corrente elétrica. As atividades experimentais propostas fomentam a evolução do perfil conceitual do estudante no sentido da ampliação da zona empírica e da definição de variáveis de observação. Este fato se deve ao estabelecimento de um roteiro que busca fo- 
mentar a "variação empírica" em detrimento da ingênua busca de "variedade" (BACHELARD, 2013, p. 27).

A partir da análise realizada neste estudo, as principais recomendações para a aplicação da sequência didática proposta são:

1. Evidenciar os conflitos cognitivos e desafiar o estudante a buscar soluções que resolvam as inconsistências e as incoerências conceituais observadas;

2. Desafiar o estudante a diferenciar os conceitos de carga elétrica e dipolo magnético; campo elétrico e campo magnético, força elétrica e força magnética, visando a superação de eventuais obstáculos epistemológicos;

3. Construir o conceito de regra da mão direita e sua aplicação na formalização da força magnética entre o campo magnético e a corrente elétrica a partir da evidência experimental pelo uso da Balança de Ampère-Faraday proposta.

\section{Conclusão}

$\mathrm{O}$ artigo apresenta o desenvolvimento de uma sequência didática para o ensinoaprendizagem conceitual de campo magnético e interação magnética, em uma abordagem experimental semiestruturada, com foco na questão das relações de simetria da interação magnética. A proposta tem como referencial teórico o modelo de utilização metodológica do conflito cognitivo como forma de fomentar o processo de ensino e aprendizagem. A abordagem proposta foi investigada na aplicação da sequência didática em uma escola secundária, dentro do contexto de uma dissertação de mestrado profissional em Ensino de Física. Os resultados foram analisados pela observação do modo de se expressar dos estudantes, dentro de um referencial teórico da Teoria de Perfis Conceituais. Em consonância com estudos reportados na literatura, observou-se que a confusão entre os conceitos de força e campo elétricos, e os conceitos de força e campo magnéticos, é um dos principais obstáculos epistemológicos à aprendizagem do tema. A abordagem metodológica proposta é relevante e objetiva ser uma alternativa à abordagem tradicional que, em geral, reforça analogias errôneas entre as simetrias do campo magnético e do campo elétrico.

\section{Referências}

AMARAL, E. M. R. do; MORTIMER E. F.; SCOTT, P. A conceptual profile of entropy and spontaneity: characterizing modes of thinking and ways of speaking in the classroom. In: MORTIMER, E. F.; EL-HANI, C. N. (Org.) Conceptual profiles: a theory of teaching and learning scientific concepts. Dordrecht: Springer Verlag, 2014. Cap. 8. p. 201-235.

AUSUBEL, D. P. The acquisition and retention of knowledge: a cognitive view. Dordrecht: Kluwer Academic Publishers, 2000. 212p. 
BACHELARD, G. A formação do espírito científico. 10. ed. Rio de Janeiro: Editora Contraponto, 2013. 316p.

CHABAY, R.; SHERWOOD, B. Restructuring the introductory electricity and magnetism course. American Journal of Physics, v. 74, p. 329-336, 2006.

CHEVALLARD, Y. On Didactic Transposition Theory: some introductory notes In: SIMPÓSIO INTERNACIONAL SOBRE DOMÍNIOS SELECIONADOS DE PESQUISA E DESENVOLVIMENTO EM EDUCAÇÃO MATEMÁTICA, Bratislava, 1988. Anais... Bratislava: [s. n.], 1989. Disponível em:

$<$ http://yves.chevallard.free.fr/spip/spip/article.php3?id_article=122>. Acesso em: 1 nov. 2012.

Readjusting Didactics to a Changing Epistemology: Conferência Européia sobre a pesquisa de Educação, Universidade de Genebra, 13-15 de setembro de 2006. In: European Educational Research Journal, [S. 1.], v. 6, n. 2, p. 9-27, 2007.

CHINN, C. A.; BREWER, W. F. The role of anomalous data in knowledge acquisition: A theoretical framework and implications for science instruction. Review of educational research, Sage Publications, v. 63, n. 1, p. 1-49, 1993.

EL-HANI, C. N.; AMARAL, E. M. R.; SEPUlVEDA, C.; MORTIMER, E. F. Conceptual Profiles: Theoretical-methodological Grounds and Empirical Studies. Procedia - Social and Behavioral Sciences, v. 167, p. 15-22, 2015.

FERNANDES, J. A. Balança de Ampère-Faraday: uma estratégia para discutir campo magnético e força magnética. 2015. 132 p. Dissertação (Mestrado Nacional Profissional em Ensino de Física) - Universidade Federal de Lavras, Lavras, 2015. Disponível em: <http://repositorio.ufla.br/jspui/handle/1/10592>.

FURIÓ, C.; GUISASOLA, J. Difficulties in learning the concept of electric field. Science Education, v. 82, p. 511-526, 1998.

GUISASOLA, J.; ALMUNDÍ, J. M.; ZUBIMENDI, J. L. Difficulties in learning the introductory magnetic field theory in the first years of University. Science Education, v. 88, p. 443464, 2004.

HENRIQUES, V. B.; PRADO, C. P. C.; VIEIRA, A. P. Editorial convidado: aprendizagem ativa. Revista Brasileira de Ensino de Física, São Paulo, v. 36, n. 4, p. 01-02, Dec. 2014. Disponível em: <http://www.scielo.br/scielo.php?script=sci_arttext\&pid=S180611172014000 400001\&lng=en \&nrm=iso>. Acesso em: 22 jun. 2017. 
KUSTUSCH, M. B. Assessing the impact of representational and contextual problem features on student use of right-hand rules. Physical Review Physics Education Research, v. 12, p. 010102, 2016.

LEPPAVIRTA, J. Assessing undergraduate students' conceptual understanding and confidence of electromagnetics. International Journal of Science and Mathematics Education, Springer, v. 10, n. 5, p. 1099-1117, 2012.

McLEOD, S. A. Cognitive Dissonance. Disponível em: <www.simplypsychoogy.org/cogni tive-dissonance.html>. Acesso em: 15 mai. 2016.

MARR, M. Development of instructional systems for teaching an electricity and magnetism course for engineers, American Journal of Physics, v. 67, p. 789-802, 1999.

MOREIRA, M. A. Subsídios teóricos para o professor pesquisador em ensino de ciências: a teoria da aprendizagem significativa. Porto Alegre, 2009.

MOREIRA, M. A. Unidades de enseñanza potencialmente significativas. Aprendizagem Significativa em Revista, v. 1, p. 43-66, 2011.

MORTIMER, E. F. Conceptual change or conceptual profile change? Science \& Education, v. 4, p. 265-287, 1995.

MORTIMER, E. F.; EL-HANI, C. N. Conceptual Profiles. A Theory of Teaching and Learning Scientific Concepts. Dordrecht: Springer Verlag, 2014. 330p.

NGUYEN, N. L.; MELTZER, D. Initial understanding of vector concepts among students in introductory physics courses. American Journal of Physics, v. 71, p. 630-638, 2003.

PÁDUA, E. M. M. Análise de Conteúdo, Análise de Discurso: questões teóricometodológicas. Revista de Educação, PUC-Campinas, Campinas, n. 13, p. 21-30, 2002.

PIAGET, J. A Psicologia da Inteligência. Petrópolis: Vozes, 2013. 249p.

PIAGET, J.; CHOMSKY, N. Teorias da linguagem, teorias da aprendizagem. Lisboa: Edições 70, 1987.

POSNER, G.; STRIKE, K.; HEWSON, P.; GERTZOG, W. Accomodation of scientific conception: Toward a theory of conceptual change. Science Education, v. 66, p. 211-227, 1982.

SAARELAINEN, M.; HIRVONEN, P. E.; LAAKSONEN, A. Students' initial knowledge of electric and magnetic fields-more profound explanations and reasoning models for undesired conceptions, European Journal of Physics, v. 28, p. 51-60, 2007.

SAARELAINEN, M.; HIRVONEN, P. E.; LAAKSONEN, A. Students' conceptions and reasoning models of the electric force and field related questions in the interviewed CSEM test. 
In: E. VAN DEN BERG (Ed.) Modelling in Physics and Physics Education. Amsterdam: University of Amsterdam, 2006.

SAARELAINEN, M. Teaching and learning of electric and magnetic fields at the university level. 2011. 112 p. Tese (Doutorado) - University of Eastern Finland, Kuopio, 2011. ISBN 978-952-61-0559-8.

SCANIO, J. J. G. Conservation of momentum in electrodynamics: an example. American Journal of Physics, v. 43, p. 258, 1975. Doi: 10.1119/1.10065

SOKOLOFF, D. R.; THORNTON, R. K. Using interactive lecture demonstrations to create an active learning environment. The Physics Teacher, v. 35, p. 340-347, 1997.

SOKOLOFF, D. R.; THORNTON, R. K. Assessing student learning of Newton's laws: The Force and Motion Conceptual Evaluation and the Evaluation of Active Learning Laboratory and Lecture Curricula. American Journal of Physics, v. 66, p. 338, 1998.

SALOMON, F.; ITZA-ORTIZ, B. A. Students' models of Newton's second law in mechanics and electromagnetism. European Journal of Physics, v. 25, p. 81-89, 2004.

SCAIFE, T. M.; HECKLER, A. F. Interference between electric and magnetic concepts in introductory physics, Physical Review Physics Education Research, v. 7, p. 010104, 2011.

SCAIFE, T. M.; HECKLER, A. F. Student understanding of the direction of the magnetic force on a charged particle. American Journal of Physics, v. 78, p. 869, 2010.

SOUZA FILHO, M. P.; BOSS, S. L. B.; CALUZI, J. J. Problematização no ensino de tópicos do Eletromagnetismo por meio das etapas da psicanálise Bachelardiana. Nuances, v. 22, p. 72-95, 2012.

VOSNIADOU, S. et al. Designing learning environments to promote conceptual change in science. Learning and Instruction, v. 15, p. 317-419, 2001. 